\title{
Mis cincuenta años en los cien de Borges ${ }^{1}$ My fifty years in the hundred of Borges
}

\author{
Noé Jitrik
}

Recibido: 10 de Marzo 2012. Aprobado: 23 de Abril de 2012

\begin{abstract}
Resumen
Este ensayo diserta sobre las posibilidades poéticas y filosóficas que suscita la lectura del texto "Borges y yo", que desde su título lanza la perspectiva de la identidad de quien escribe y de quien lee. La necesidad de ubicar el acto de la lectura como experiencia fenomenológica, entrega al lector la oportunidad de rehacer el texto confrontando las diversas "realidades" convocadas en la estética "borgiana".
\end{abstract}

Palabras Clave: Jorge Luís Borges; Literatura argentina; literatura latinoamericana

\begin{abstract}
This paper expounds on the poetic and philosophical possibilities raised text reading "Borges y yo", which since its launch title phenomenological perspective of the identity of the writer and of the reader. The need to locate the act of reading as a phenomenological experience, provides the reader the opportunity to redo the text confronting the various "realities" called in "Borgiana" aesthetic.
\end{abstract}

Keywords: Jorge Luís Borges; Argentina literature; Latin American literature.

En la sesión inaugural de un encuentro que tiene como tema un título por lo menos provocativo, "Borges y yo", celebrado en junio de 1999, mi amigo, el escritor Mario Goloboff se mostró muy extrañado por el título de algo que llamaba pomposamente la "ponencia": ¿qué es eso de los cincuenta años en los cien de Borges? Y hoy, como reencontrándose con ese apunte de perplejidad - y denunciándome -, otra escritora y amiga, Martha Mercader, me dijo, no sin franqueza: “ipero vos tenés más de cincuenta años!” Es cierto: tenía más en ese momento, pero eso no era novedad al menos para mí, pero eso es menos significativo que la aclaración que ambas y espontáneas reacciones merecen.

${ }^{1}$ Escrito en 1999. Ensayo resultado de las investigaciones del autor en el Instituto de Letras de la Universidad de Buenos Aires.

Poligramas 37, primer semestre 2013, ISSN 0120-4130. 
La imagen de los cincuenta años es nada más y nada menos que un punto de partida. Se trata de una noche, que recuerdo muy bien, de hace algo más de cincuenta años: era un sábado y yo estaba, solo, en el bar "La Fragata", que ya no existe más, en Corrientes y San Martín; yo tenía 20 años y en mis manos lo único que había era el volumen de los Poemas de Borges, de la edición de Losada, que reunía sus primeros libros. Esa imagen persiste, está instalada en mí, e inaugura una serie que se va completando en cincuenta años, me costaba referir esta cantidad de tiempo a mi persona, naturalmente mucho más ahora, transcurridos trece temibles años. El hecho es que, desde 1948 hasta ahora, la aparición casi constante de Borges en encuentros y desencuentros hacen una crónica de mis cincuenta años que están como incrustados o recortados en los cien de Borges. Eso quiere decir el título que propuse y que tenía, creo, la limpidez necesaria como para hacerse aceptar en este coloquio porque respondía, me parece, a la incitación implicada en su consigna, “Borges y yo". Recordé en ese momento, mejor dicho "me” recordé en ese sábado por la noche en Buenos Aires y pienso que esa imagen es, ya, un relato de una desdicha: un chico de 20 años, solo, lejos de la fiesta, leyendo poesía junto a una mesa de un café, la imagen es acaso un poco patética pero también puede ser poética. Ya casi no recuerdo los versos que sé muy bien que me transportaban, sólo una frase persiste, es nada más que un título, “Ultimo sol en Villa Ortúzar"; por supuesto es una imagen, quizás una descripción pero también es una resonancia: ahora me parece que en el juego que se establece entre la esdrújula que la inicia y esa grave fuerte posterior reside su probable poder de perduración, su garantía de conservación de una magia incitadora, me parece que no como sonido sino como imagen tiene que ver con una estructura muy borgiana que, años después, hice un poco mía; me refiero a las caminatas, recorrer Buenos Aires en los años posteriores al regreso de Europa él en su momento yo en el mío, apropiarse de la ciudad caminando y establecer una ecuación entre los pies, los ojos y la escritura: caminaba para ver y luego escribía y si el escrito se prolongaba en sonidos entonces brotaba la poesía. Puedo decir ahora que esos primeros libros de poemas de Borges, Luna de enfrente, Fervor de Buenos Aires, Cuadernos San Martín son, años después lo pude ver, tal vez un circuito lógico y previsible pero que en otros que no sean Borges no incluyen el tercer término y por lo 
general ni siquiera el segundo, caminan pero no ven y menos escriben. En cambio, se da en Borges algo análogo a lo que se puede leer en el primer libro de Roberto Arlt, El juguete rabioso, que es algo así como una historia de caminatas que derivan en una dramática de escritura: y si bien en ambos, contemporáneamente, es más que evidente el deseo de hacer un descubrimiento de Buenos Aires, "mitológica", también es cierto que se tiende por debajo, como un sostén, una teoría de la escritura que si en Borges tiene un respaldo vanguardista en Arlt es una intuición precursora. En Borges, ese descubrimiento o redescubrimiento instaura una continuidad, esos poemas son el punto de partida de todos sus avatares posteriores; en Arlt se hace fantasía de subterráneos morales, crónica de minucias sociales caracteropáticas. No menciono estos recuerdos tenues, que no llegan ni a anécdota, ni estas relaciones, porque sí; tal vez sean el elemento de convicción que me hizo aceptar la invitación de Saúl Sosnowski de quien -no puedo evitar hacer un chiste, malo fuera de duda, cuyo pie me lo dio el propio Sosnowski al mencionar el apellido de Héctor (Yánover, ya no ver) vinculándolo con Borges: su apellido es como de Barón báltico, quizás de mariscal, aunque yo prefiero decir que es más de formalista ruso, dimensión más acorde con la atmósfera en la que todos nosotros nos movemos. Pues la invitación es “Borges y yo" y ese título, que al mismo tiempo recupera una llamada borgiana, propone un deslizamiento tan riesgoso como delicado. Por de pronto hace brotar otra imagen: incita, como desplazamiento, un desplazamiento de pebeteros, quiero decir que la columna de incienso se va del lado de Borges y se dirige tenuemente hacia "yo". "Yo" puede sentir el breve vértigo de un enunciado en primera persona cuyo objeto es el enunciador mismo, ése que cuando aparece el nombre de Borges se elide por fuerza, sufriendo la elisión, o de buena gana, con sincera modestia. La propuesta abre a esa posibilidad.

Pero hace un momento, Héctor Yánover y Saúl Sosnowski, al abrir el encuentro, evitaron ese riesgo y volvieron a hablar de Borges, no de ellos mismos, acaso porque querían ser consecuentes con la invitación a los demás a hablar de sí mismos, es decir a hablar de "yo". Y yo, yo, me pregunto quién es "yo". Porque si lo que predica la frase "Borges y yo" dibuja el contorno de un lugar en el que los dos términos conviven horizontalmente, también nos pone en un terreno ambiguo, es difícil sostener que ese sintagma de horizontalidad nos 
incluye aunque en nuestro foro interno sintamos lo contrario, o sea que nos incluye. Augusto Monterroso, en uno de sus luminosos momentos, escribió algo como esto: "a ningún escritor le gusta que le digan que es bueno; ni siquiera le gusta que le digan que es excelente; lo único que satisface a un escritor es que le digan que es el mejor del mundo"; en otras palabras, que "yo y Borges", adviértase el nuevo desplazamiento de los términos, estamos en el mismo espacio, con el mismo derecho a la palabra, "yo" podría, por lo tanto, abrirse a "mi mismo" y su palabra lo tendría por objeto. Y, aunque todo esto parezca un poco chusco, no lo es más que la verdad, una verdad tan fuerte que si uno no creyera eso tampoco podría empezar a escribir, lo cual se entiende mejor si se presenta por la negativa: ¿acaso tiene sentido escribir para ser un "peor”? Pero, desde luego, estas cosas no se deben decir, quien las dice se condena. Sea como fuere, decir "Borges y yo" postula que bien puede ser que estemos en el mismo charco pero, la realidad es en ese sentido muy cruel, no es exactamente así, hay una historia de tal relación: ¿quién es yo? ¿Quién sería yo? Para salir del enredo propongo una variable, tal vez se podría pensar en otra frase, por ejemplo "Borges y tu". Creo, con toda sinceridad, que tal cambio facilitaría las cosas porque abriría a las historias de una relación. Por ejemplo, veía en ese momento a Roberto Fernández Retamar y recordé que lo primero que hicimos al conocernos -fue en 1967 y era mi primer desembarco en Cuba-, fue hablar de Borges; creo que hablamos mal de él, tomamos distancia, coincidimos en lo que podía por esos años ser considerado una perversión, la situación de Borges como intelectual responsable, no su obra, que quedaba a salvo; volvíamos a aislar esa magnífica prosa, esa bellísima poesía, esa inteligencia excepcional en los ensayos, separándolas de aquello otro que nos perturbaba; y, aunque las fuentes de la perturbación fueran diferentes para cada uno, las coincidencias entusiastas nos permitieron iniciar y mantener una conversación, y eso no es poca cosa. "Borges y tú" también me hace pensar en la circunstancia y el modo en que cada uno de esos "tú" vivió a Borges al acercarse por primera vez; por ejemplo, mi primer encuentro con Juan José Saer, en 1959, a orillas de la laguna Setúbal, en esa Santa Fe cuyo secreto Saer trata sin descanso de develar, fue una batalla campal; él sostenía que quien no pensara que Borges era lo máximo era si no un cretino una especie de atrasado mental o bien un reaccionario en el sentido más 
profundo de la palabra. Y yo, que creo que soy más contemplativo o moderado, decía "bueno, no es para tanto, no ha de ser tan así, bien podemos poner alguna distancia para poder entender algo de una situación compleja, por lo menos compleja”. Del encontronazo, y eso es historia, me surgió una idea que, por supuesto, como pude comprobarlo después, durante todos los años de nuestra relación, no involucraba a Saer, en él el arrebato debía ser leído en otro registro; la idea era que si por un lado había Borges, con todo lo suyo, también existía una subclase, una secta abominable de borgianos cuyo discurso, para decirlo en términos nacionales, tenía algo de competencia entre equipos de fútbol: había que gritar "Viva Borges" porque no hacerlo implicaba apoyar al enemigo, para el caso los escritores penosamente realistas. Ese modo de defender a Borges no fue, considerado en su historia, fácil de soportar.

Pero "Borges y tú" no se me agota en esas dos situaciones; la frase me envía a muchas otras; veo aquí a mi viejo amigo Marcelo Abadi que, muy adelantado, profesaba, también él, un culto borgiano; apenas ingresó a la Facultad de Filosofía y Letras y nos conocimos me mostró uno de sus primeros textos en el que sobresalía esta frase, "un mito audazmente forjado", que debe ser interpretada como un homenajea Borges, que aún no era un mito audazmente forjado; para mí Borges era sólo una primera entonación de su poesía, expresión desde luego muy vaga, pero, al parecer, podía ser que la admiración por Borges acarreara otras consecuencias.

¿La experiencia de lectura que ofrecía obligaba a seguir sus pasos? ¿De qué manera? Ordenando un poco mis ideas y vinculándolas con lo que emana de la figura de Borges, yo diría que hay tres modos de responder a esa pregunta. El primero responde a la noción de “influencia”. Ya se sabe: es una noción trivial y casi abandonada por los discursos literarios más serios; sin embargo, debe darse, debe poder verificarse en la práctica, sin duda Borges debe ejercer influencia en algunos escritores y en algunos textos de modo que, en ese caso, difícilmente "Borges y tú" pueda llegar a convertirse en "Borges y yo" porque sise admite que se ha sufrido la "influencia de" se renuncia a ser uno mismo, individual e intransferible. Como, de todos modos, nadie se subordina hasta tal punto, pese a que puede admitir que así 
ha sucedido, la noción de "influencia" sólo la enuncian los historiadores y los críticos, no suelen hacerlo los escritores.

Hacía pocos meses, en un encuentro celebrado en Austin, como es obvio sobre Borges, Tomás Eloy Martínez me dio la idea de un segundo modo de respuesta a una lectura de Borges; habló de un pernicioso "mandato" emanado de ese artículo de Borges tan trasegado, tan invocado, Los escritores argentinos y la tradición, en el que parece residir el núcleo de su poética, su deóntica; Tomás sostenía en ese encuentro -y creo que siguió haciéndolo después- que el "mandato" de Borges había sido hacer una literatura sin cuerpo, despojada, una literatura más o menos mentalizada o bien, en última instancia, separada de lo más característico de la tradición literaria argentina y sobre todo de la latinoamericana, a saber, en apariencia, lo corporal, lo físico; ese mandato implicaba eliminar el cuerpo, con todo lo que eso significa. Tal hipótesis podía ser discutida y lo fue; yo no sé qué es lo corporal tratándose de escritura, no puede ser sólo lo referencial, no puede ser sólo el desborde pasional, bien puede haber pasión en las ideas, en la continuidad, en un deseo cuyo lenguaje puede ser oculto o disfrazado.

En cuanto al tercer modo, en mi opinión el más difícil de asir o precisar, es el más prometedor para cualquier consideración de la irradiación que pudo haberse producido de la obra de Borges; me refiero a la noción de "presencia". ¿En qué puede consistir la presencia de Borges en un conjunto literario? ¿De qué manera se manifiesta esa presencia teniendo en cuenta que la noción misma de presencia no es fácil de definir, no se sabe muy bien qué es una presencia, amenos que se sea heideggeriano y se admita la redundancia como salida filosófica. Pero veamos, hay frases sugerentes que incluyen la palabra presencia o la noción misma de presencia. Por comenzar, se puede decir que presencia es aparición: tal vez es el sentido que le da Steiner cuando habla de "Presencias reales", como la posibilidad de una ratificación. Pero aun así la noción no se agota, sigue siendo enigmática la idea de presencia y, sobre todo, qué y cómo puede ser el reconocimiento, como presencia, de las huellas que en ciertos escritores deja otro. En cuanto concierne a Borges parecería que hay un consenso o un acuerdo acerca de la presencia que tiene en otros, y no sólo en la 
Argentina ni en América Latina sino aparentemente también en otros lugares o en otras literaturas del mundo.

¿En qué consiste la presencia de Borges? le he estado dando vueltas al tema desde hace un tiempo. En cierto momento, hace algunos años, se me ocurrió que en la narrativa latinoamericana -en la poesía es otra cosa- había sobre todo dos polos ordenadores y un tercero excluido. Tales polos, de manera esquemática, podían encarnarse en figuras que aparecen como exitosas. Noción también ambigua; el éxito se supone tanto en la realización como en la aceptación que tiene lo realizado y, luego, en su proyección desde una perspectiva trascendente, en relación con procesos más amplios; desde luego, esta noción no es la trivial, reúne un haz de perspectivas así como exige el respaldo de diversas teorías y, bajo su amparo, podría decirse que las dos figuras eran, por un lado Borges y, por el otro, García Márquez, como dos líneas que no obstante sus muy diferentes alcances en algún punto se encuentran. Dejando de lado esta posibilidad y ateniéndonos tan sólo a la imagen de la polaridad, uno y otro, olas respectivas obras, funcionan como ordenadores del conjunto de la narrativa latinoamericana. Esta forma de clasificación puede ser como cualquier otra pero, al menos, tendría la virtud de permitir la salida de los límites nacionales y de entender confluencias, presencias, con precisión, más o menos evidentes. A partir de ahí se podría hacer una clasificación, hay quienes devienen inteligibles porque se protegen en una figura o en la otra, sin necesidad de apelar a la ayuda de la noción de influencia aunque, en algunos casos, tanto en la línea de García Márquez como en la de Borges, la influencia es tan innegable que llega a la imitación. Esto no quiere decir que las dos líneas no se tocan para nada; en algún trabajo que hice hace muchos años sobre García Márquez me pareció ver huellas de Borges, me pareció que las resonancias borgianas eran indudables, más por evocaciones y por imágenes que por el sentido de la escritura o de la prosa.

$\mathrm{Y}$, en cuanto al tercero excluido, que siempre llega oportunamente para superar los pares, era en mi opinión el realismo tradicional latinoamericano que, no obstante su fidelidad a sus principios originarios y rectores, algo había recibido de las dos líneas principales. Las Experiencias Borges y García Márquez lo habían matizado y lo estaban llevando a realizar

Poligramas 37, primer semestre 2013, ISSN 0120-4130. 
determinadas experiencias de escritura en lasque, no obstante, perduraba, como elemento central, la atención al referente real, en las que el conflicto y la situación o los personajes, era tan determinantes como siempre; más aún, tales impregnaciones lo estaban llevando a la zona de la autobiografía como salida a su persistencia; en suma, realismo subsistente pero al mismo tiempo sensible a todas las transformaciones poéticas que las líneas García Márquez y Borges podían ofrecer o estaban brindando ya al conjunto de la literatura latinoamericana.

Desde este esquema, podemos volver al tema de la presencia. Talvez se trata, para detectarlas, tan sólo de experiencias de lectura; o bien reside en declaraciones o bien son observaciones que se pueden hacer desde el exterior, luego de un minucioso examen textual, como por ejemplo afirmar que en la obra narrativa de José Emilio Pacheco la presencia de Borges es indudable, no es necesario que él la declare, está ahí, no es sólo la evidente glosa de "El milagro secreto" sino la insistencia en la "incisión", el "inc", que tiene que ver con inquirir, inquisición, relato de enigma, etcétera. Borges, entonces, ordena no sólo un conjunto de situaciones o de temas sino de significantes, campo en el que quizás resida la persuasividad extraordinaria de la obra de Borges, ciertos núcleos significantes como prueba de una fecundidad- pueden ordenar un pensamiento y también una escritura.

La idea de presencia es, entonces, al mismo tiempo seductora y evasiva, fugitiva, es posible determinarla pero cómo hacerlo, qué caminos seguir. En el caso de la poesía me parece que es diferente: la primera poesía de Borges tiene presencia o yo la puedo percibir.

Decir esto me permite retomar la situación inicial, el "yo", acerca de cuya consistencia física y metafísica hice algunas observaciones.

Pero me refiero a la primera poesía, no a la segunda ni a la tercera, a la menos trascendente, la que si Borges no hubiera llegado a ser quien fue podía tal vez ser puesta en un sitio menos considerable; de todos modos, en cuanto a "yo", puedo decir que esa poesía me hizo escribir aunque de su acción me doy cuenta tardíamente, muchos años después, como si hubiera residido en mí como una fuente oculta cuyas aguas emergieron y me hicieron seguir un camino en lugar de otro; yo creo que se escribe, sobre todo poesía, creyendo que se escribe experiencias pero en realidad también se escribe lecturas, no las inmediatas sino

Poligramas 37, primer semestre 2013, ISSN 0120-4130. 
las que se han decantado y depositado en el subterráneo de la memoria. Yo pensé que empezaba a escribir impulsado por mis lecturas de Eliot o Apollinaire pero en realidad, visto en perspectiva, también pienso que me impulsó a escribir Borges, sin seguirlo deliberadamente y sin saberlo, sólo ahora, casi a los cincuenta años de esta frecuentación, puedo quizás advertirlo en mi mismo para hablar de ese mi, o sea de "yo", en proceso, no como de alguien situado en determinado terreno. Pero si reconozco esa poesía en mí no creo, con toda franqueza, que el resto de la poesía de Borges se reconozca demasiado en otros poetas; se lo puede invocar, se lo puede homenajear, se pueden hacer citas de sus poemas pero no me parece que haya dejado una estela o, al menos, me cuesta reconocerlo.

Podría intentarse; en ese caso habría, para advertir esa presencia, que entender un movimiento de simpatía semejante a la que liga al propio Borges con la escritura de Macedonio Fernández, aun cuando él lo haya negado; lo hizo -me lo recordaba hoy mismo Adelaida Fernández Retamar- mediante ese elogio tan especioso que le dedica, a saber que Macedonio era mejor conversador que escritor. Pero, respecto de mí, así como veo en otros presencias de Borges veo en ella de Macedonio: por supuesto no es una imitación, por supuesto no es un seguidismo, una presencia semejante es difícil de determinar o de explicar, pero se percibe en ciertas continuidades, relacionadas en particular con estrategias de ruptura, en lo sintáctico y en lo conceptual, que yo diría que son "interesantes", en el sentido pleno de la palabra, o sea que "interesa" e interesa sentir y destacar.

Para terminar con este "yo" viene a cuento, por asociación necesaria más que libre, la frase de Pascal, "todo yo es odioso", que en la corrección que le hace Gide, "todo yo es efectivamente odioso, salvo el mío", se liga con la "boutade" de Monterroso: el yo de cada uno es lo más importante del mundo, cosa que los yoes de los demás, como es natural, no reconocen puesto que los de ellos son eso mismo, lo más importante del mundo. Se produce una colisión: ese choque hace que los relatos en primera persona se vean a veces interrumpidos; cuando la enunciación comienza con ese "yo" que a los demás les parece que se superpone al propio la conexión se rompe aunque la puerta sigue abierta, pese a la interrupción. 
En mi caso, como nadie por ahora me está interrumpiendo y quizás por cortesía se deja que mi "yo" se explaye, diría que la mención a los cincuenta años con la que empecé esta plática se prolonga en encuentros, fascinaciones y desencuentros que tienen que ver con un largo proceso en la literatura argentina y latinoamericana. Así, para retomar, viene bien preguntarme por qué llegó Borges a mí cuando yo tenía apenas veinte años y mis ausencias en materia de lecturas eran todavía mayores que las actuales. ¿Por qué apareció Borges? ¿Me lo impusieron? ¿Quién me lo impuso? Quizás la razón no fue literaria sino espuriamente política en el sentido de que Borges encarnaba en esos años, del 45 al 50, el escritor perseguido por el peronismo. Y como siempre se necesita identificarse con alguien para validar los enconos y las oposiciones seguro que vi en él una posibilidad que me llevó a leerlo. Eso, más allá de lo que ocurrió conmigo, fue bastante general e hizo de un escritor casi secreto e íntimo una contrafigura, con tal éxito, pero también con tales costos, que muchos suponen, o postulan, que la vida útil de toda una generación que empieza en esos años, del 45 en adelante, estuvo a la sombra de Perón y de Borges que son, por eso mismo, los fantasmas que hay que conjurar o, con más modestia, los monumentos que hay que sacarse de encima para poder seguir viviendo. En este momento pareciera que es más fácil reducir a Perón, es más difícil hacerlo con Borges quizás porque, resonando en tantos rincones de, así la podemos llamar, "la patria literaria", tampoco uno "quiere" sacárselo de encima de ese modo, el deseo es el problema.

Este es, además, un punto de difícil tratamiento en la Argentina; las figuras, como en el siglo XIX, son todavía muy determinantes de las posiciones y de las éticas globales de la existencia y por la misma razón las adhesiones. Incluso tal vez para mí, por esa razón tan poco crítica, Borges fue de entrada indispensable; no mucho después, por suerte, se convirtió en fascinante: en 1951, cuando aún era estudiante, me animé a leer Otras inquisiciones, que acababa de aparecer, ya escribir sobre ese libro; recuerdo haber puesto una frase que quizás sea la mejor intuición que he tenido sobre Borges. Y era la idea de la pasión intelectual, que como imagen se me aparecía en ese momento como posibilidad de conciliar o de salirse de este tipo de discusión tan nacional, quizás tan argentina, aunque no ha de ser de su exclusividad, acerca del pensamiento y la acción, el pensamiento suele ser 
separado de la acción, el pensamiento considerado como la no acción, el intelectual en última instancia como sospechoso, como perverso y el activo, que vaya uno a saber quién podría ser, como un ideal; dicho de otro modo, entre una figura de escritor reconcentrado y problemático como Ezequiel Martínez Estrada, por ejemplo, y el Hemingway fotografiado junto a un león abatido, por no hablar de otra clase de héroes, la opinión votaba por Hemingway aunque, después de todo también era un escritor, en realidad eran otras proezas las más atractivas y atrayentes, las del deporte, las del cine, las de la política, las de la delincuencia inclusive. En esa atmósfera tan vitalista, que siempre traté de combatir, a mí me pareció que en ese libro de Borges se podía sentir, quien estuviera en condiciones de hacerlo, una verdadera pasión, una pasión intelectual. Publiqué esa nota en una revista estudiantil y luego me olvidé de ella y de Borges por un tiempo hasta que tuve una revelación en París, como corresponde: tuve una percepción, una idea, una sensación cuando asistí a algo así como el momento en el que Borges empezaba a tomar la forma de un mito. En una reunión que siento ya como mitológica por el solo hecho de mencionar a quienes estaban allí -Jean Wahl, Roger Caillois, Paul Benichou, entre otros- se hablaba de él con proyección de futuro: en menos de 10 años esa profecía se cumplió y Europa y la caída del peronismo fueron determinantes para ello. Yo creo que lo que se dijo en esa tarde de octubre o noviembre de 1953 fue revelador, sólo tal vez porque respondía, al menos en mi reflexión de entonces, a un movimiento muy propio de la cultura argentina: empezamos a valer si valemos en Europa, no valemos tanto si sólo valemos aquí, la soledad que emana de las pampas contamina el prestigio y lo hace relativo y liviano, eso mismo que había comprendido Sarmiento cuando mostró su Facundo en París, un poco más de un siglo antes. Siento, por lo tanto, que ahí empezó, en mi presencia y la de Marcelo Abadi, que asistíamos, provincianos asombrados, a un alumbramiento, a ese impresionante fenómeno de difusión que culminó en este año, fuera ya de toda duda su grandeza y su posición de intocable y de universal, de factor de interpretación de la forma de la cultura toda del siglo XX. 
Y, en ese lugar y para retomar la consigna, se podría, ahora, teológicamente, proclamar: Borges hay uno solo, y "yo" soy su profeta, una frase como ésa resolvería todos los conflictos a los que me referí al comienzo.

En el entretanto los desencuentros predominaban en mi historia relacionada con Borges. En especial, una idea: si Borges no estaba de nuestro lado, políticamente hablando, como se ha dicho y se dirá hasta el tedio -apoyos terribles, rechazos inaceptables, distancias reprobables-, en su obra misma podía haber indicadores de por qué no estaba de nuestro lado. De mi parte, o de nuestra parte porque acaso era un signo de una época y rasgo de un grupo, el demonio de la coherencia nos arrasó, vivíamos en lo que después se llamó la "era de la sospecha”. Basados en la aplicación muy rigurosa no tanto del pensamiento marxista sino más bien de alguno de sus traductores, tipo Hauser, Luckacs o sus seguidores locales, la coherencia entre la formulación exterior y el pensamiento íntimo era un fantasma que nos perseguía; si Borges no estaba de nuestro lado, si Borges empezaba a partir de esos años a emitir opiniones que considerábamos como políticamente reaccionarias algo en su obra debía funcionar mal, algo en su obra debía ser reaccionario, la concepción misma de su obra o de su prosa debía serlo, la perfección, por ejemplo, podía ser reaccionaria, ahí nomás estaba el ejemplo de Lugones o el de Kipling o el de Bloy. En el punto de la coherencia subían a la escena las nefastas filosofías inspiradoras: Berkeley, el idealismo, las teologías, un lejano Maunthner, el rechazo al marxismo y al psicoanálisis y todo ese paradigma mental calificable desde el lugar en el que nos situábamos. Con los años tal vez se pueda advertir que más bien era un juego, el gran juego, no una afirmación sustancial o sustancialista sino un modo de ir entramándose con una noción de realidad que pasaba más allá de la experiencia concreta o de las definiciones concretas para ir también a considerar los objetos mentales como objetos reales, con los cuales se podía establecer una relación de transformación, de deformación, de parodia, de punto de partida, de todoel universo borgiano y que es una fuga permanente de la posibilidad de asirlo y de quedarse en él, con una lectura unívoca.

Ese modo de ver las cosas, esa búsqueda de coherencia, en lo personal, otra vez el "yo", hizo que yo no intentara acercarme a él; no me arrepiento porque pienso que no pasa por

Poligramas 37, primer semestre 2013, ISSN 0120-4130. 
una proximidad física la posibilidad de analizar lo que a uno le ocurre con una obra pero también es la secreta razón de los sucesivos y divertidos desencuentros que se produjeron y que traté de narrar en mi trabajo Sentimientos complejos sobre Borges, mediante el cual creí en su momento que saldaba todas mis cuentas. 